\title{
Contribution of flow-volume curves to the detection of central airway obstruction*
}

\author{
Contribuição da curva de fluxo-volume na detecção de obstrução da via \\ aérea central
}

\author{
Liliana Bárbara Perestrelo de Andrade e Raposo, António Bugalho, \\ Maria João Marques Gomes
}

\begin{abstract}
Objective: To assess the sensitivity and specificity of flow-volume curves in detecting central airway obstruction (CAO), and to determine whether their quantitative and qualitative criteria are associated with the location, type and degree of obstruction. Methods: Over a four-month period, we consecutively evaluated patients with bronchoscopy indicated. Over a one-week period, all patients underwent clinical evaluation, flow-volume curve, bronchoscopy, and completed a dyspnea scale. Four reviewers, blinded to quantitative and clinical data, and bronchoscopy results, classified the morphology of the curves. A fifth reviewer determined the morphological criteria, as well as the quantitative criteria. Results: We studied 82 patients, 36 (44\%) of whom had CAO. The sensitivity and specificity of the flow-volume curves in detecting CAO were, respectively, 88.9\% and 91.3\% (quantitative criteria) and 30.6\% and 93.5\% (qualitative criteria). The most prevalent quantitative criteria in our sample were FEF50\%/FIF50\% $\geq 1$, in 83\% of patients, and FEV1/PEF $\geq 8 \mathrm{~mL}$. $\mathrm{L}^{-1}$. $\mathrm{min}^{-1}$, in 36\%, both being associated with the type, location, and degree of obstruction $(p<0.05)$. There was concordance among the reviewers as to the presence of CAO. There is a relationship between the degree of obstruction and dyspnea. Conclusions: The quantitative criteria should always be calculated for flow-volume curves in order to detect CAO, because of the low sensitivity of the qualitative criteria. Both FEF50\%/FIF50\% $\geq 1$ and FEV $1 / \mathrm{PEF} \geq$ $8 \mathrm{~mL} . \mathrm{L}^{-1} \cdot \mathrm{min}^{-1}$ were associated with the location, type and degree of obstruction.
\end{abstract}

Keywords: Bronchoscopy; Maximal expiratory flow-volume curves; Sensitivity and specificity; lung neoplasms.

\section{Resumo}

Objetivo: Verificar a sensibilidade e especificidade das curvas de fluxo-volume na detecção de obstrução da via aérea central (OVAC), e se os critérios qualitativos e quantitativos da curva se relacionam com a localização, o tipo e o grau de obstrução. Métodos: Durante quatro meses foram selecionados, consecutivamente, indivíduos com indicação para broncoscopia. Todos efetuaram avaliação clínica, preenchimento de escala de dispneia, curva de fluxo-volume e broncoscopia num intervalo de uma semana. Quatro revisores classificaram a morfologia da curva sem conhecimento dos dados quantitativos, clínicos e broncoscopicos. Um quinto revisor averiguou os critérios morfológicos e quantitativos. Resultados: Foram incluídos 82 doentes, 36 (44\%) com OVAC. A sensibilidade e especificidade da curva de fluxovolume na detecção de OVAC foram, respectivamente, de 88,9\% e 91,3\% (critérios quantitativos) e de 30,6\% e 93,5\% (critérios qualitativos). Os critérios quantitativos mais frequentes na amostra foram o FEF50\%/FIF50\% $\geq 1 \mathrm{em} 83 \%$ e o VEF1/PFE $\geq 8 \mathrm{~mL}$. $\mathrm{L}^{-1} \cdot \mathrm{min}^{-1} \mathrm{em} 36 \%$ dos doentes, e ambos se relacionaram com o tipo, a localização e o grau de obstrução $(p<0,05)$. Houve concordância dos revisores quanto à existência ou não de OVAC. Existe relação entre o grau de obstrução e o de dispneia. Conclusões: Os critérios quantitativos devem ser sempre calculados nas curvas de fluxo-volume de forma a detectar OVAC, dado a baixa sensibilidade dos critérios qualitativos. Os critérios FEF50\%/ FIF50\% $\geq 1$ e VEF1/PFE $\geq 8 \mathrm{~mL} \cdot \mathrm{L}^{-1}$. min $^{-1}$ foram relacionados com a localização, o tipo e o grau de obstrução.

Descritores: Broncoscopia; Curvas de fluxo-volume expiratório máximo; Sensibilidade e especificidade; Neoplasias pulmonares.

*Study carried out at the Respiratory Pathophysiology Section, Department of Pulmonology, Northern Lisbon Hospital Center, Lisbon, Portugal.

Correspondence to: Liliana Andrade e Raposo. Rua Cesário Verde, 39, 2 Direito, Queijas, 2790-491, Oeiras, Portugal.

Tel. 35121 754-8547. E-mail: liliana.raposo@ cardiocvp.net

Financial support: None.

Submitted: 31 January 2013. Accepted, after review: 16 July 2013. 


\section{Introduction}

Central airway obstruction (CAO) is a pathological process that leads to airflow limitation at the level of the glottis, subglottis, trachea, and main bronchi. Correct diagnosis and treatment of CAO is an area of interest and concern for health professionals, given that this disease has the potential to cause significant morbidity and mortality.

The incidence and prevalence of CAO are unknown; however, the epidemiological characteristics of lung cancer worldwide and the increase in survival resulting from the use of treatments that are more efficient indicate that there is an increasing number of patients with invasion of the proximal airway. Ernst et al. ${ }^{(1)}$ emphasize that $20-30 \%$ of patients with lung cancer develop complications related to CAO, whereas Cavaliere et al. ${ }^{(2)}$ estimate that $35 \%$ of lung neoplasms cause obstruction of the trachea and main bronchi. Worrisome values have been published by Miyazawa et al., who state that CAO can affect 50\% of patients with lung cancer. ${ }^{(3)}$ In Portugal, the number of deaths from malignant tumors of the lung, trachea, and main bronchi increased from 1.5\%, in 1981, to $2.28 \%$, in 2008 , which allows for speculation about an increase in the incidence of CAO. ${ }^{(4)}$

Given the absence of specificity and the subjectivity of the symptoms that characterize CAO, there is a need to implement diagnostic methods that are efficient in evaluating this disease. Several studies have shown that rigid or flexible bronchoscopy is necessary for the definitive diagnosis of CAO, and that only by using these techniques is it possible to visualize and characterize the nature, degree, and extent of the lesions directly. ${ }^{(5-7)}$ Although these tests make it possible to acquire knowledge about the etiology and the structural nature of CAO, they are invasive and provide no information about the pathophysiological impact. Respiratory function testing, by means of analysis of flowvolume curves obtained from forced maneuvers, is the most appropriate method. ${ }^{(1,8,9)}$

Flow-volume curves are a graphic representation of airflow determined at different volumes, having been used for detecting CAO since the late 1960s. They became a subject of interest when some authors proposed the ratio between forced expiratory and inspiratory flows at $50 \%$ of FVC $\left(\mathrm{FEF}_{500_{0}} / \mathrm{FIF}_{500^{\circ}}\right) \geq 1$ as the first quantitative diagnostic criterion for CAO. ${ }^{(10,11)}$
Subsequently, other criteria were made available, namely $\mathrm{FEV}_{1} / \mathrm{PEF} \geq 10 \mathrm{~mL} . \mathrm{L}^{-1} \cdot \mathrm{min}^{-1}, \mathrm{FIF}_{50 \%}$ $<100 \mathrm{~mL}$, and $\mathrm{FEV}_{1} / \mathrm{FEV}_{0.5} \geq 1.5 .^{(12,13)} \ln 2005$, Pellegrino et al. suggested that $\mathrm{FEV}_{1} / \mathrm{PEF} \geq 8$ $\mathrm{mL} \cdot \mathrm{L}^{-1} \cdot \mathrm{min}^{-1}$ can indicate the presence of CAO and recommended performing ancillary tests to confirm the disease. ${ }^{(14)}$ Likewise, there are qualitative or morphological changes obtained from visual analysis of flow-volumes curves that can contribute to the diagnosis of CAO and that include the presence of a plateau on the inspiratory portion of the flow-volume curve (variable extrathoracic obstruction), a plateau on the expiratory portion of the curve (variable intrathoracic obstruction), and a plateau on the inspiratory and expiratory portions (fixed obstruction). ${ }^{(11,12)}$

Most studies on this topic were published many years ago, have methodological flaws, and show a lack of standardization. In addition, recent technological developments, namely those related to the diagnostic methods and the sophistication of the new spirometers, have not produced significant advances in this area. The generalized notion that the presence of the quantitative and qualitative criteria always raises the suspicion of CAO needs confirmation.

The primary objective of the present study was to determine whether flow-volume curves are a sensitive and specific method for detecting CAO. As secondary objectives, we sought to establish whether the quantitative criteria are associated with the location, type, and degree of obstruction; whether there is a criterion that best identifies the presence of CAO; whether CAO can be present without affecting the morphology of the curve; and whether there is an association between the degree of obstruction and the degree of dyspnea.

\section{Methods}

Between November of 2009 and April of 2010, we conducted a prospective, observational, cross-sectional study. The target population consisted of patients for whom bronchoscopy was clinically indicated. The patients were consecutively selected for the sample on the basis of the following inclusion criteria: being clinically indicated for bronchoscopy (with or without suspected (AO); being able to undergo respiratory function tests, especially flow-volume curve measurement; and giving written informed consent. The exclusion criteria included having 
hemodynamic instability; being unable to undergo flow-volume curve measurement, meeting quality control standards; being under 18 years of age; having contraindications to undergoing bronchoscopy or flow-volume curve measurement; and declining to participate in the study. The study was approved by the Health Ethics Committee of the Northern Lisbon Hospital Center, and all of the patients gave written informed consent after the objectives of the study were explained to them, verbally and in writing.

Each patient underwent a brief physical examination, and the degree of dyspnea was determined by the Medical Research Council (MRC) 5-point scale. ${ }^{(15)}$

Bronchoscopy was performed with a flexible bronchoscope (BF-P180, Olympus, Tokyo, Japan), which was introduced into the nasal or oral cavity and advanced to the vocal folds and lower airway, with the bronchial tree reached by the device being seen throughout its length, bilaterally. The changes were recorded according to the classification proposed by Freitag et al. to describe the degree, type, and location of obstruction. ${ }^{(16)}$

The flow-volumes curves were measured by a cardiorespiratory technician with a previously calibrated plethysmograph (Vmax 6200; SensorMedics, Yorba Linda, CA, USA). The procedures were performed in accordance with the guidelines proposed by the American Thoracic Society/European Respiratory Society Task Force in 2005. ${ }^{(14)}$ At least three flowvolume curves were measured, two of which were reproducible, meeting the recommended quality control criteria. The best curve was chosen on the basis of the sum of the best FVC and the best FEV $_{1}$. Inspiratory values were calculated using the curve that obtained the best inspiratory effort, i.e., the greatest $\mathrm{FIF}_{50 \%}$.

For each patient, the maximum interval between functional, clinical, and endoscopic evaluation was one week. The collected data were recorded on a form designed specifically for this study.

Subsequently, copies of the morphology of the flow-volume curves (without the quantitative parameters) were made, being compiled randomly. In order to determine agreement between the morphology of the curve and the identification or exclusion of CAO, four reviewers, who were experienced in performing respiratory function tests and interpreting their results and who were blinded to the results of the remaining evaluations (quantitative or bronchoscopic), were requested to classify the curves in terms of their morphology by means of a Likert scale: 1) not at all suggestive of $\mathrm{CAO} ; 2$ ) slightly suggestive of CAO; 3) reasonably suggestive of CAO and 4) highly suggestive of CAO. A fifth independent reviewer performed all quantitative and qualitative calculations for the curves.

The Statistical Package for the Social Sciences, version 17.0 (SPSS Inc., Chicago, IL, USA), was used for data treatment. The tests used included the nonparametric Mann-Whitney test (for ordinal variables measured in two independent samples) and Pearson's and Spearman's correlation coefficients (for nominal and ordinal variables). A binomial regression analysis was performed to determine the sensitivity and specificity of the flow-volume curves, with obstruction confirmed by bronchoscopy being the dependent variable and each of the quantitative and qualitative criteria of the curve being the independent variables. The sample was characterized using descriptive statistics. When applicable, the $95 \%$ or $99 \%$ confidence intervals of the tests used in this study were calculated.

\section{Results}

Over a four-month period, we consecutively evaluated 107 patients. Of those, 25 (23\%) were excluded because they did not meet the inclusion criteria: 8 (32\%) because it was not possible to determine the degree of obstruction; 6 (24\%) because their flow-volume curve measurements failed to meet quality standards; 9 (36\%) because they had hemodynamic instability; and 2 (8\%) because they declined to participate in the study. Of the remaining 82 patients, 36 (44\%) had CAO confirmed by bronchoscopy. The patients were divided into two groups: those with and those without CAO. The demographic characteristics are described in Table 1, which shows the lack of statistically significant differences between the two groups in mean age, gender, and smoking history. Regarding the reasons (i.e., diagnoses) motivating bronchoscopy, the group of patients with CAO included 30 (83\%) with malignant lung cancer and $6(17 \%)$ with benign disease, whereas the group without CAO included 26 (56.5\%) for whom malignant cancer was confirmed and 20 (43.5\%) for whom benign disease was confirmed. 
Table 1 - Demographic characteristics of the study sample. ${ }^{\text {a }}$

\begin{tabular}{lcc}
\hline Variable & Bronchoscopy showing CA0 & Bronchoscopy showing no CA0 \\
\cline { 2 - 3 } & $(\mathrm{n}=36)$ & $(\mathrm{n}=46)$ \\
\hline Age, years & 64.5 & 61.7 \\
Male/female gender & $23(64) / 13(36)$ & $34(74) / 12(26)$ \\
Smoker & $23(64)$ & $29(63)$ \\
Smoking history, pack-years ${ }^{\mathrm{b}}$ & 52 & 63 \\
Malignant/benign etiology & $30(83.0) / 6(17.0)$ & $26(56.5) / 20(43.5)$ \\
\hline
\end{tabular}

CA0: central airway obstruction. ${ }^{a}$ Values expressed as $n(\%)$, except where otherwise indicated. ${ }^{b}$ Values expressed as mean.

Table 2 - Sensitivities and specificities of the criteria of flow-volume curves.

\begin{tabular}{lcccc}
\hline Criteria & Sensitivity, \% & Specificity, \% & $\begin{array}{c}\text { Positive predictive } \\
\text { value, \% }\end{array}$ & $\begin{array}{c}\text { Negative predictive } \\
\text { value, } \%\end{array}$ \\
\hline Quantitative & 88.9 & 91.3 & 88.9 & 91.3 \\
Qualitative & 30.6 & 93.5 & 78.6 & 63.2 \\
Quantitative + & 93.9 & 89.8 & 86.1 & 95.6 \\
Qualitative & & & & \\
\hline
\end{tabular}

Table 3 - Correlation of the quantitative and qualitative criteria with the location of obstruction.

\begin{tabular}{|c|c|c|c|c|c|c|c|c|c|c|}
\hline \multirow[t]{2}{*}{ Quantitative criteria } & \multicolumn{2}{|c|}{$\begin{array}{l}\text { Upper third of } \\
\text { the trachea }\end{array}$} & \multicolumn{2}{|c|}{$\begin{array}{l}\text { Middle third } \\
\text { of the trachea }\end{array}$} & \multicolumn{2}{|c|}{$\begin{array}{l}\text { Lower third of } \\
\text { the trachea }\end{array}$} & \multicolumn{2}{|c|}{ RMB } & \multicolumn{2}{|c|}{ LMB } \\
\hline & $r$ & $p$ & $r$ & $p$ & $r$ & $p$ & $r$ & $p$ & $r$ & $p$ \\
\hline $\mathrm{FEF}_{50 \%} / \mathrm{FIF}_{50 \%} \geq 1$ & -3.327 & 0.001 & -1.317 & 0.188 & 2.309 & 0.021 & -3.781 & 0.000 & 2.500 & 0.012 \\
\hline $\mathrm{FEV}_{1} / \mathrm{PEF} \geq 10 \mathrm{~mL} \cdot \mathrm{L}^{-1} \cdot \mathrm{min}^{-1}$ & -0.400 & 0.690 & -0.158 & 0.874 & -7.393 & 0.000 & -2.569 & 0.010 & 0.615 & 0.539 \\
\hline $\mathrm{FEV}_{1} / \mathrm{PEF} \geq 8 \mathrm{~mL} \cdot \mathrm{L}^{-1} \cdot \mathrm{min}^{-1}$ & -0.070 & 0.944 & -0.434 & 0.664 & -2.478 & 0.013 & -3.166 & 0.002 & 0.629 & 0.529 \\
\hline $\mathrm{FEV}_{1} / \mathrm{FEV}_{0.5} \geq 1.5$ & -0.927 & 0.354 & -3.559 & 0.000 & -4.051 & 0.000 & -1.811 & 0.070 & 1.093 & 0.274 \\
\hline \multicolumn{11}{|l|}{ Qualitative criteria } \\
\hline Morphology & & & 0.257 & 0.020 & 0.386 & 0.001 & 0.490 & 0.000 & & \\
\hline
\end{tabular}

$\mathrm{FEF}_{50 \%}$ : forced expiratory flow at 50\% of $\mathrm{FVC} ; \mathrm{FIF}_{50 \%}$ : forced inspiratory flow at 50\% of FVC; RMB: right main bronchus; and LMB: left main bronchus.

Table 4 - Association of the quantitative and qualitative criteria with the type of obstruction.

\begin{tabular}{|c|c|c|c|c|c|c|}
\hline \multirow[t]{2}{*}{ Quantitative criteria } & \multicolumn{2}{|c|}{ Intraluminal } & \multicolumn{2}{|c|}{ Extraluminal } & \multicolumn{2}{|c|}{ Mixed } \\
\hline & $r$ & $\mathrm{p}$ & $r$ & $\mathrm{p}$ & $r$ & $\mathrm{p}$ \\
\hline $\mathrm{FEF}_{50 \%} / \mathrm{FIF}_{50 \%} \geq 1$ & 0.491 & 0.000 & 0.361 & 0.001 & -0.019 & 0.866 \\
\hline $\mathrm{FEV}_{1} / \mathrm{PEF} \geq 10 \mathrm{~mL} \cdot \mathrm{L}^{-1} \cdot \mathrm{min}^{-1}$ & 0.057 & 0.608 & 0.334 & 0.002 & 0.259 & 0.019 \\
\hline $\mathrm{FEV}_{1} / \mathrm{PEF} \geq 8 \mathrm{~mL} \cdot \mathrm{L}^{-1} \cdot \mathrm{min}^{-1}$ & 0.264 & 0.016 & 0.226 & 0.041 & 0.134 & 0.228 \\
\hline $\mathrm{FEV}_{1} / \mathrm{FEV}_{0.5} \geq 1.5$ & 0.002 & 0.983 & 0.230 & 0.037 & 0.101 & 0.367 \\
\hline \multicolumn{7}{|l|}{ Qualitative criteria } \\
\hline Morphology & 0.313 & 0.004 & 0.126 & 0.260 & 0.137 & 0.219 \\
\hline
\end{tabular}

$\mathrm{FEF}_{50 \%}$ : forced expiratory flow at 50\% of FVC; and $\mathrm{FlF}_{50 \%}$ : forced inspiratory flow at 50\% of FVC. 
Table 5 - Association of the quantitative and qualitative criteria with the degree of obstruction.

\begin{tabular}{lcc}
\hline Quantitative criteria & $\mathrm{r}$ & $\mathrm{p}$ \\
\hline $\mathrm{FEF}_{50 \%} / \mathrm{FIF}_{50 \%} \geq 1$ & 0.673 & 0.000 \\
$\mathrm{FEV}_{1} / \mathrm{PEF} \geq 8 \mathrm{~mL} . \mathrm{L}^{-1} \cdot \mathrm{min}^{-1}$ & 0.325 & 0.003 \\
Qualitative criteria & & \\
Morphology & 0.271 & 0.014 \\
\hline
\end{tabular}

$\mathrm{FEF}_{50 \%}$ : forced expiratory flow at 50\% of $\mathrm{FVC}$; and $\mathrm{FlF}_{50 \%}$ : forced inspiratory flow at 50\% of FVC.

The sensitivity and specificity of the flowvolume curves were determined, and, at this point, the quantitative and qualitative criteria were used alone and in combination (Table 2). The combined use of all of the quantitative and qualitative criteria was found to keep specificity high (89.8\%), allowing an increase in sensitivity (93.9\%).

With the purpose of determining whether professionals are attentive to the morphological aspects of flow-volume curves, a frequency count test and Spearman's correlation were used to assess agreement among the reviewers. The results show that the reviewers agreed among themselves, heading in the same direction with a $95 \% \mathrm{Cl}$, i.e., they either headed in favor of or against the presence of obstruction.

The correlation of the quantitative and qualitative criteria with the location of obstruction was studied with the nonparametric Mann-Whitney test and Pearson's correlation (Table 3). Statistically significant differences were found among the patients who met the criterion of having an $\mathrm{FEF}_{500 \%} / \mathrm{FIF}_{50 \%} \geq 1$ for all locations, except for that in the middle third of the trachea. Both $\mathrm{FEV}_{1} / \mathrm{PEF} \geq 10 \mathrm{~mL} . \mathrm{L}^{-1} \cdot \mathrm{min}^{-1}$ and $\mathrm{FEV}_{1} / \mathrm{PEF} \geq 8$ $\mathrm{mL} . \mathrm{L}^{-1} \cdot \mathrm{min}^{-1}$ were present when the obstruction was located in the lower third of the trachea or in the right main bronchus (RMB; $p<0.05$ ). When the obstruction was located in the middle and lower thirds of the trachea, $\mathrm{FEV}_{1} / \mathrm{FEV}_{0.5} \geq 1.5$ was present $(p<0.01)$. The qualitative criteria were associated with the obstruction being located in the middle and lower thirds of the trachea and in the RMB $(p<0.01)$.

Pearson's and Spearman's correlations were used to investigate a possible association of the quantitative and qualitative criteria with the type of obstruction (Table 4). The results showed that $\mathrm{FEF}_{50 \%} / \mathrm{FIF}_{50 \%} \geq 1$ and $\mathrm{FEV} / \mathrm{PEF} \geq 8 \mathrm{~mL} . \mathrm{L}^{-1} \cdot \mathrm{min}^{-1}$ were associated with intraluminal and extraluminal obstruction. The criterion of having an $\mathrm{FEV}_{1} /$
$\mathrm{PEF} \geq 10 \mathrm{~mL} \cdot \mathrm{L}^{-1} \cdot \mathrm{min}^{-1}$ was found in the presence of extraluminal or mixed obstruction ( $p<0.05$ ), and $\mathrm{FEV}_{1} / \mathrm{FEV}_{0.5} \geq 1.5$ was found in the presence of extraluminal obstruction. Regarding the qualitative criteria, morphological changes in the curve were found in the presence of intraluminal obstruction $(p<0.01)$.

Regarding the correlation of the quantitative and qualitative criteria with the degree of obstruction, Spearman's correlation was used (Table 5). We found that the two criteria that were most associated with the degree of obstruction were $\mathrm{FEF}_{500 /} / \mathrm{FIF}_{50 \%} \geq 1$ and $\mathrm{FEV}_{1} / \mathrm{PEF} \geq 8 \mathrm{~mL}$. $\mathrm{L}^{-1} \cdot \mathrm{min}^{-1}$. For the quantitative and qualitative (morphological) criteria, this correlation was positive, i.e., a higher degree of obstruction translated to an increased likelihood of finding the aforementioned morphological changes and quantitative criteria.

Spearman's correlation was used to assess the presence of dyspnea and the location of obstruction. The presence of dyspnea was found to correlate with the obstruction being located in the upper third of the trachea $(p<0.05)$, as well as with the degree of obstruction $(p<0.05)$, this correlation being positive, i.e., a higher degree of obstruction translated to a higher patientreported degree of dyspnea.

\section{Discussion}

The present study demonstrated that the quantitative criteria of flow-volume curves have high sensitivity and high specificity in detecting $\mathrm{CAO}$, and that the morphological criteria have low sensitivity but high specificity. These data underscore the need for careful inspection of the morphology of the curves, although the need for a quantitative evaluation of the values for all curves is mandatory.

The evaluation and treatment of patients with CAO require in-depth knowledge of its etiology, physiology, diagnosis, and treatment options. The study of each individual should include multiple aspects, chief among which are the clinical component (signs and symptoms), the pathophysiological impact (respiratory function), and imaging studies (chest CT and techniques for airway endoscopy). The compilation of such data, together with etiology, is an important factor in establishing prognosis, determining the need for treatment, or planning a future therapeutic intervention. Regarding etiology, 
the study population included patients with CAO due to benign stenosis, in most cases following intubation, and due to malignant stenosis, in the context of tumor invasion of the proximal airway, which confirms the high prevalence of these diseases. ${ }^{(1,2)}$

From a pathophysiological standpoint, the literature reports that, when CAO is mild, there can be little or no reduction in airflow, with the patient remaining asymptomatic at rest or dyspneic on exertion, and that, in the presence of marked obstruction of the trachea, symptoms occur at rest. ${ }^{(1,5,9)}$ Likewise, our results confirm an association between the degree of dyspnea and that of obstruction. In addition, we found that there is an association between any given degree of dyspnea, as measured by the MRC scale, and the presence of obstruction in the upper third of the trachea.

A factor of great importance is that this symptom is common to many diseases of the cardiorespiratory system, which is why the hypothesis of CAO is not often raised. The request of flow-volume curves is common in these patients, and our study shows the presence of CAO with no qualitative changes in the curve. We can speculate that this result is due to the number of smokers included in the group of patients with CAO. A significant smoking history can translate to underlying chronic obstructive pulmonary disease, which is likely to cause changes in the morphology of flow-volume curves, and this is consistent with the international literature. ${ }^{(1,16)}$ Quantitative calculations, performed systematically, would make it possible to increase the diagnostic yield for CAO.

There was good agreement among the individuals who reviewed the morphology of the flow-volume curves as to the presence or absence of CAO, which demonstrates that they were sensitized to the presence of morphological changes that could lead to the identification of CAO. These results are in line with those of Watson et al., who used a similar methodology to detect morphological changes in the flowvolume curve that were consistent with vocal cord dysfunction. ${ }^{(17)}$ Recently, Sterner et al. evaluated 2,662 flow-volume curves in order to determine whether the changes of the inspiratory phase would be consistent with the presence of CAO. ${ }^{(18)}$ In only $50 \%$ of the patients was the presence of CAO confirmed. Once again, this draws attention to the need to meet the quality criteria by means of the quantitative determination for all flow-volume curves.

Although the qualitative criteria were identified nearly 40 years ago, we found only two other studies conducted in order to assess the sensitivity of flow-volume curves in detecting CAO: that of Miller et al. ${ }^{(19)}$ and that of Modrykamien et al. ${ }^{(20)}$

The first study reports sensitivity values of 100\% and specificity values of 78\% for the qualitative criteria. The difference in the methodology used, namely the study population (100\% of patients with goiter and extrinsic compression), could explain the observed difference from our results, because our patients mostly had intraluminal disease of malignant origin.

The second study demonstrates that the qualitative criteria have a sensitivity of 5.5\% and a specificity of $93.6 \%$. These results are in line with those found in our study. The methodological similarity shared by the two studies, namely the characteristics of the study population, may have led to this closeness of results.

When the morphological changes were associated with the location of obstruction, the results indicate a correlation of the quantitative criteria with obstruction in the lower two-thirds of the trachea and in the RMB. These data are in line with those of a study by Hira \& Sing, ${ }^{(21)}$ who found morphological changes in the curve that were associated with obstruction at the level of the trachea.

Regarding the association with the type of obstruction, it was only possible to find it in the presence of intraluminal obstruction. Most patients with CAO (75\%) had this type of obstruction, and, finding no studies in the literature that support these results, one can infer that, because of the small number of patients with this type of changes in our sample, other associations were not found.

Our results showed that $\mathrm{FEF}_{50 \%} / \mathrm{FIF}_{50 \%} \geq 1$ was the most common quantitative criterion in patients with CAO (in 83\%), similarly to what was published in the studies of Miller \& Hyatt, ${ }^{(10)}$ of Yernault et al., ${ }^{(11)}$ and also of Das et al., ${ }^{(2)}$ who found this criterion in $86.5 \%$ of their sample. In addition, this criterion was found to be associated with all locations of CAO, except for that in the middle third of the trachea. The study of Rotman et al. ${ }^{(13)}$ and that of Hira \& Sing ${ }^{(21)}$ were similar, associating this criterion with the presence of extrathoracic obstruction. 
The second most prevalent criterion in this study was FEV $/ \mathrm{PEF} \geq 8 \mathrm{~mL} \cdot \mathrm{L}^{-1} \cdot \mathrm{min}^{-1}$ (in $36 \%$ of our sample). Previous studies suggest that this criterion is extremely important in detecting CAO, as in the study of Miller et al., ${ }^{(21)}$ who found a specificity of 94\% and a specificity of $64 \%$ in patients with CAO due to goiter. Similar results were also found by Brooks \&t Fairfax, ${ }^{(23)}$ who identified the presence of this criterion in a study presenting three cases of patients with CAO confirmed by flexible bronchoscopy.

Similarly to the previous criterion, $\mathrm{FEV}_{1} / \mathrm{PEF} \geq$ $8 \mathrm{~mL} \cdot \mathrm{L}^{-1} \cdot \mathrm{min}^{-1}$ was associated with CAO in the lower third of the trachea or in the RMB, as well as with intraluminal and extraluminal obstruction. Once again, we emphasize that our results are original, given that there are no other studies in the scientific literature that have sought to answer this question.

We underscore the need for future studies on this topic. Some of our questions of investigation could not be compared with those of previous studies because there are no such studies. It is possible that the methodology of the present study, namely the sample size, which did not allow us to assess a significant number of patients with each degree of obstruction and each location of obstruction, may have contributed to our results. In the future, we suggest a study involving a larger sample size in order to form significant groups of patients with CAO in different locations.

The present study showed that flow-volume curves contribute significantly to the detection of $\mathrm{CAO}$, and that these curves can lead to a more rapid diagnosis, translating to economic benefits and predominantly to benefits in patient quality of life.

\section{References}

1. Ernst A, Feller-Kopman D, Becker HD, Mehta AC. Central airway obstruction. Am J Resp Crit Care Med. 2004;169(12):1278-97. http://dx.doi.org/10.1164/ rccm.200210-1181S0 PMid:15187010

2. Cavaliere S, Venuta F, Foccoli P, Toninelli C, La Face B. Endoscopic treatment of malignant airway obstruction in 2,008 patients. Chest. 1996; 12;110(6):1536-42.

3. Miyazawa T, Miyazu Y, lwamoto Y, Ishida A, Kanoh $\mathrm{K}$, Sumiyoshi $\mathrm{H}$, et al. Stenting at the flow-limiting segment in tracheobronchial stenosis due to lung cancer. Am J Respir Crit Care Med. 2004;169(10):1096-102. PMid:15132959

4. Oliveira, 1. Mortalidade: Compressão, Deslocamento e Causas de Morte. Rev Estudos Demográficos. 2008;48(1):35-76.

5. Jeon K, Kim H, Yu CM, Koh WJ, Suh GY, Chung MP, et al. Rigid bronchoscopic intervention in patients with respiratory failure caused by malignant central airway obstruction. J Thorac Oncol. 2006;1(4):319-23. http://dx.doi.org/10.1097/01243894-200605000-00009 PMid:17409877

6. Ernst A, Silvestri GA, Johnstone D; American College of Chest Physicians. Interventional pulmonary procedures: Guidelines from the American College of Chest Physicians. Chest. 2003;123(5):1693-717. http://dx.doi.org/10.1378/ chest.123.5.1693

7. Asimakopoulos G, Beeson J, Evans J, Maiwand MO. Cryosurgery for malignant endobronchial tumors: analysis of outcome. Chest. 2005;127(6):2007-14. http://dx.doi. org/10.1378/chest.127.6.2007 PMid:15947313

8. Kvale PA, Selecky PA, Prakash UB; American College of Chest Physicians. Palliative care in lung cancer: ACCP evidence-based clinical practice guidelines (2nd edition). Chest. 2007;132(3 Suppl):368S-403S.

9. Herzog H, Keller R, Allgöwer M. Special methods of diagnosing and treating obstructive diseases of the central airways. Chest. 1971;60(1):49-67. http://dx.doi. org/10.1378/chest.60.1.49 PMid:5571274

10. Miller RD, Hyatt RE. Obstructing lesions of larynx and trachea: clinical and physiologic characteristics. Mayo Clin Proc. 1969;44(3):145-61. PMid:5776050

11. Yernault JC, Englert M, Sergysels R, De Coster A. Upper airway stenosis: a physiologic study. Am Rev Respir Dis. 1973;108(4):996-1000. PMid:4741896

12. Empey DW. Assessment of upper airway obstruction. $\mathrm{Br}$ Med J. 1972;3(5825):503-5. http://dx.doi.org/10.1136/ bmj.3.5825.503 PMid:5069620 PMCid:PMC1785761

13. Rotman HH, Liss HP, Weg JG. Diagnosis of upper airway obstruction by pulmonary function testing. Chest. 1975;68(6):796-9. http://dx.doi.org/10.1378/ chest.68.6.796 PMid:1192859

14. Pellegrino R, Viegi G, Brusasco V, Crapo RO, Burgos F, Casaburi R, et al. Interpretative strategies for lung function tests. Eur Respir J. 2005;26(5):948-68. http://dx.doi. org/10.1183/09031936.05.00035205 PMid:16264058

15. Nouraei SA, Nouraei SM, Randhawa PS, Butler CR, Magill JC, Howard DJ, et al. Sensitivity and responsiveness of de Medical Research Council dyspnoea scale to the presence and treatment of adult laryngotracheal stenosis. Clin Otolaryngol. 2008;33(6):575-80 http://dx.doi. org/10.1111/j.1749-4486.2008.01832.x PMid:19126132

16. Freitag L, Ernst A, Unger M, Kovitz K, Marquette $\mathrm{CH}$. A proposed classification system of central airway stenosis. Eur Respir J. 2007;30(1):7-12. http://dx.doi. org/10.1183/09031936.00132804 PMid:17392320

17. Watson MA, King CS, Holley AB, Greenburg DL, Mikita JA. Clinical and lung-function variables associated with vocal cord dysfunction. Respir Care. 2009;54(4):467-73. PMid:19327181

18. Sterner JB, Morris MJ, Sill JM, Hayes JA. Inspiratory flow-volume curve evaluation for detecting upper airway disease. Respir Care. 2009;54(4):461-6. PMid:19327180

19. Miller MR, Pincock AC, Oates GD, Wilkinson R, Skene-Smith H. Upper airway obstruction due to goitre: detection, prevalence and results of surgical management. Q J Med. 1990;74(274):177-88. PMid:2345786

20. Modrykamien AM, Gudavalli R, McCarthy K, Liu X, Stoller JK. Detection of upper airway obstruction with spirometry results and the flow-volume loop: a comparison of quantitative and visual inspection criteria. Respir Care. 2009;54(4):474-9. PMid:19327182 
21. Hira HS, Singh H. Assessment of upper airway obstruction by pulmonary function testing. J Assoc Physicians India. 1994;42(7):531-4. PMid:7868521

22. Das AK, Davanzo LD, Poiani GJ, Zazzali PG, Scardella AT, Warnock ML et al. Variable extrathoracic airflow obstruction and chronic laryngotracheitis in Gulf War veterans. Chest. 1999;115(1):97-101. http://dx.doi. org/10.1378/chest.115.1.97 PMid:9925068

23. Brookes GB, Fairfax AJ. Chronic upper airway obstruction: value of flow volume loop examination in assessment and management. J R Soc Med. 1982;75(6):425-34. PMid:7086791 PMCid:PMC1437964

\section{About the authors}

\section{Liliana Bárbara Perestrelo de Andrade e Raposo}

Cardiorespiratory Diseases Technician. Respiratory Pathophysiology Section, Department of Pulmonology, Northern Lisbon Hospital Center and Portuguese Red Cross School of Health, Lisbon, Portugal.

\section{António Bugalho}

Pulmonologist and Coordinator. Interventional Pulmonology Section, Beatriz Ângelo Hospital, Loures, Portugal; and Centro de Estudo de Doenças Crônicas - CEDOC, Center for the Study of Chronic Diseases - Universidade Nova de Lisboa School of Medical Sciences, Lisbon, Portugal.

\section{Maria João Marques Gomes}

$\mathrm{PhD}$ in Pulmonology. Universidade Nova de Lisboa School of Medical Sciences, Lisbon, Portugal. 